Full length article

\title{
Natural outdoor environments and mental and physical health: Relationships and mechanisms
}

\author{
Margarita Triguero-Mas a,b,c,*, Payam Dadvand a,b,c , Marta Cirach a,b,c, David Martínez ${ }^{\text {a,b,c }}$, Antonia Medina ${ }^{\text {d }}$, \\ Anna Mompart ${ }^{\mathrm{e}}$, Xavier Basagaña ${ }^{\mathrm{a}, \mathrm{b}, \mathrm{c}}$, Regina Gražulevičienè ${ }^{\mathrm{f}}$, Mark J. Nieuwenhuijsen ${ }^{\mathrm{a}, \mathrm{b}, \mathrm{c}}$ \\ a Centre for Research in Environmental Epidemiology (CREAL), Barcelona, Spain \\ b Universitat Pompeu Fabra (UPF), Barcelona, Spain \\ c CIBER Epidemiología y Salud Pública (CIBERESP), Barcelona, Spain \\ d Departament de Salut de la Generalitat de Catalunya, Barcelona, Spain \\ e Institut d'Estadísitca de Catalunya, Barcelona, Spain \\ ${ }^{\mathrm{f}}$ Vytauto Didžiojo Universitetas, Kaunas, Lithuania
}

\section{A R T I C L E I N F O}

\section{Article history:}

Received 21 October 2014

Received in revised form 19 January 2015

Accepted 22 January 2015

Available online 30 January 2015

\section{Keywords:}

Green spaces

Blue spaces

Mental health

Social support

Physical activity

Medication

\begin{abstract}
A B S T R A C T
Background: Evidence is growing for the beneficial impacts of natural outdoor environments on health. However, most of the evidence has focused on green spaces and little evidence is available on health benefits of blue spaces and about possible mediators and modifiers of such impacts. We investigated the association between natural outdoor environments (separately for green and blue spaces) and health (general and mental) and its possible mediators and modifiers.

Methods: Cross-sectional data from adults interviewed in Catalonia (Spain) between 2010 and 2012 as part of the Catalonia Health Survey were used. The collected data included sociodemographic characteristics, self-perceived general health, mental health, physical activity and social support. Indicators of surrounding greenness and access to natural outdoor environments within $300 \mathrm{~m}$ of the residence and degree of urbanization were derived for residential addresses. Associations were estimated using logistic regression and negative binominal models. Results: Green spaces were associated with better self-perceived general health and better mental health, independent of degree of urbanization. The associations were more consistent for surrounding greenness than for access to green spaces. The results were consistent for different buffers, and when stratifying for socioeconomic status. Slightly stronger associations were found for women and residents of non-densely populated areas. No association was found between green spaces and social contacts and physical activity. The results for blue spaces were not conclusive.

Conclusion: Green spaces are associated with better general and mental health across strata of urbanization, socioeconomic status, and genders. Mechanisms other than physical activity or social support may explain these associations.
\end{abstract}

(c) 2015 Elsevier Ltd. All rights reserved.

\section{Introduction}

Natural outdoor environments, especially green spaces, have been associated with better objective and subjective physical health including: self-perceived health (Maas et al., 2006; Mitchell and Popham, 2007; De Vries et al., 2013, 2003; Wheeler et al., 2012; Maas et al., 2009; Mitchell et al., 2011), well-being (White et al., 2013a), longevity (Mitchell et al., 2011; Mitchell and Popham, 2008), cardiovascular diseases (Pereira et al., 2013; Tamosiunas et al., 2014), recovery from illness (Ulrich, 1984), symptoms experienced (De Vries et al., 2003), and

\footnotetext{
* Corresponding author at: CREAL - Centre for Research in Environmental Epidemiology, Barcelona Biomedical Research Park, Dr. Aiguader, 88, 08003 Barcelona, Spain.

E-mail address: mtriguero@creal.cat (M. Triguero-Mas).
}

birth outcomes (Donovan et al., 2011; Dadvand et al., 2014) among others.

Natural outdoor environments have also been associated with better mental health including: general mental health (De Vries et al., 2013; Strum and Cohen, 2014), psychological well-being (Kaplan, 2001); perceived mental health (De Vries et al., 2003; White et al., 2013a; Sugiyama et al., 2008; Richardson et al., 2013; Alcock et al., 2014), anxiety (Beyer et al., 2014; Chang and Chen, 2005), stress, depression, and/ or anxiety symptoms (Beyer et al., 2014; Reklaitiene et al., 2014), anxiety or mood disorder treatment (Nutsford et al., 2013), and stressrelated illnesses (Grahn and Stigsdotter, 2003). Most of the available studies on the impact of natural outdoor environments on mental health have focused on only one aspect of mental health (De Vries et al., 2003, 2013; White et al., 2013a; Strum and Cohen, 2014; Sugiyama et al., 2008; Alcock et al., 2014; Chang and Chen, 2005; 
Reklaitiene et al., 2014; Nutsford et al., 2013; Grahn and Stigsdotter, 2003; Astell-Burt et al., 2014; Van den Berg et al., 2010; White et al., 2013b). These studies therefore lack the comprehensive view that would be provided by considering a full range of indicators.

There is some evidence suggesting that the associations between natural outdoor environments and health might be stronger for low socioeconomic statuses (SES) (Mitchell and Popham, 2007; De Vries et al., 2003; Mitchell and Popham, 2008; Dadvand et al., 2014), and might vary by gender (Tamosiunas et al., 2014; Reklaitiene et al., 2014; Astell-Burt et al., 2014; Richardson and Mitchell, 2010) and degree of urbanization (Mitchell and Popham, 2007; De Vries et al., 2003). But these differences are still not well-established. Moreover, various mechanisms (increasing physical activity (De Vries et al., 2013; Sugiyama et al., 2008; Richardson et al., 2013), increasing social contacts (De Vries et al., 2013; Maas et al., 2009; Sugiyama et al., 2008), increasing restoration/ stress reduction (De Vries et al., 2013; Roe et al., 2013), and decreasing environmental hazard exposure (Dadvand et al., 2012a)) have been suggested to explain the associations between green space and health (De Vries et al., 2013), but there is not a clear understanding of them yet (Nieuwenhuijsen et al., 2014; Hartig et al., 2014). Furthermore, little research has been conducted regarding types or characteristics of green spaces that may improve people's health (De Vries et al., 2013; Nieuwenhuijsen et al., 2014; Adevi and Grahn, 2011). Most of the existing studies have been performed in the northwest of Europe and the US, and the applicability of their conclusions to other parts of the world is uncertain (Nieuwenhuijsen et al., 2014). Finally, most of available evidence on the health effects of natural outdoor environment has focused on green spaces and the available studies on potential health benefits of blue spaces (i.e. sea, lakes, urban water bodies, etc.) are still very scarce (Nieuwenhuijsen et al., 2014).

The overarching aim of this study was to evaluate the association between natural outdoor environments (separately for green and blue spaces) and health (general and mental). We also investigated whether this association was modified by the degree of urbanization, gender or socioeconomic status and mediated by physical activity or social support.

\section{Methods}

\subsection{Study population}

Our study used data from adults being interviewed at the first five campaigns (2010-2012) of the ESCA (Enquesta de Salut de Catalunya) $(\mathrm{n}=8793)$ (Supplementary materials - page 8). The ESCA is a multistage stratified randomized population-based survey in Catalonia, Spain. Catalonia is located in the north-east of the Iberian Peninsula, with an area of $32,107 \mathrm{~km}^{2}$ and 7,478,968 inhabitants in 2013 (Generalitat de Catalunya, 2014). It has a Mediterranean climate characterized by hot and dry summers, mild winters, and maximum precipitation and vegetation during autumn and spring.

The ESCA is conducted by the Catalonia Health Department. It aims to study the health status, life-styles and use of health services among Catalonia residents (Alcañiz-Zanón et al., 2014). It is structured in continuous interviewing campaigns (eight six-month campaigns). Around 2400 people are interviewed in each campaign. It started in 2010 and it will finish in 2014 (Alcañiz-Zanón et al., 2014). As part of the EC funded PHENOTYPE study (Nieuwenhuijsen et al., 2014) we assigned indicators for natural outdoor environments and evaluated the relationship between these and health indicators.

\subsection{Health indicators}

Various health indicators were derived from the ESCA questionnaire:

a) Self-perceived general health: Participants answered the question from the 36-items Short-Form Health Survey (SF-36) (Ware and
Donald Sherbourne, 1992). Question was: "In general, would you say that your health is ...", and potential answers were excellent/ very good/good/moderate/bad. The answers were dichotomized with cut-off at "less than good", following the same methodology used by others (Maas et al., 2006; De Vries et al., 2003).

b) Perceived risk of poor mental health: Participants answered the twelve questions of the General Health Questionnaire (GHQ-12) (Goldberg and Williams, 1991). The four possible answers of each question were dichotomized as present/absent (Supplementary materials - page 3). Then the score from zero to twelve was dichotomized with cut-off at three, following the same methodology used by others (Rocha et al., 2013).

c) Perceived depression and/or anxiety: Participants answered if they suffered or had suffered from depression and/or anxiety. They could respond: yes/no.

d) Visits to mental health specialists: Participants answered if they had visited the psychiatrist and/or psychologist during the last year. They could respond: yes/no.

e) Intake of medication: Participants answered if they had taken (i) tranquilizers or sedatives, (ii) antidepressants, or (iii) sleeping medication in the last two days. They could respond: yes/no. These questions included medications prescribed by a doctor, suggested by a pharmacist, and self-prescribed.

\subsection{Mediator indicators}

Social support and physical activity were derived from the ESCA questionnaire:

a) Social support: Participants answered the eleven questions of the Duke-UNC Functional Social Support (DUFSS) (Broadhead et al., 1988). The five values that were possible answers of each question (Supplementary materials - page 5 ) were summed up to produce a total score ranging from 11 to 55 , following the same methodology used by others (Pino et al., 2014). Then, to be able to model it, we adjusted its distribution to a negative binomial using a new variable defined as the maximum of the index (55) minus the observed value.

b) Physical activity: Participants answered four questions of the Welsh Heart Health Survey (Heartbeat Wales, 1989). Following the physical activity recommendations or not was derived dichotomizing the answers (Supplementary materials - page 6) with a cut-off at "less than 600 Metabolic Equivalent of Task (MET) minutes per week", following the World Health Organization recommendations (World Health Organization, 2010).

\subsection{Natural outdoor environment indicators}

Assessment of exposure to natural outdoor environments was based on residential address and it focused on two aspects: access to natural outdoor environments (including green and blue spaces) and surrounding greenness. Accordingly, three indicators of exposure were developed including surrounding greenness, access to green spaces, and access to blue spaces. We characterized these indicators in a circular buffer of $300 \mathrm{~m}$ around geocoded address of residence of each participant, following previous studies for surrounding greenness (Balseviciene et al., 2014) and European Commission recommendations for access to green spaces (European Commission, 2001), and taking into account that it has been suggested that after $300-400 \mathrm{~m}$ of distance the use of natural outdoor environments decline (Annerstedt et al., 2012).

Surrounding greenness was determined as the average of the Normalized Difference Vegetation Index (NDVI). It was derived from the Landsat 8 satellite images provided at $30 \mathrm{~m} \times 30 \mathrm{~m}$ spatial resolution. 
NDVI is an indicator of green vegetation density based on the difference between visible red and near-infrared surface reflectance. NDVI values range from -1 to +1 , with higher values indicating high density of green vegetation (Weier and Herring, 2014). To cover the entire study region, we required four Landsat images. We aimed to find cloud-free images within the greenness season (April to July) during 2009-2013, the relevant years to our study. Based on this search we obtained four images for July 2013: 5th for Barcelona and 12th for Lleida, Aran and Ebre regions. We used the NDVI data excluding big water bodies, following PHENOTYPE project guidelines (Supplementary material page 7).

Access to natural outdoor environments was characterized by its surrogate residential proximity to natural outdoor environments. Two different indicators were developed. First, access to green spaces was defined as the presence or not of green spaces within the $300 \mathrm{~m}$ circular buffer. The included green spaces were green urban areas, agricultural land and pastures, and non-urban green areas like forests or country parks. Second, access to blue spaces was defined as the presence or not of blue space within the same buffer. The natural outdoor environments were derived from CORINE Land Cover 2006 (CLC2006) at $1: 100,000$ resolution and minimum represented units of 25 ha, with an addition of a polygon representing the sea. The included blue spaces were inland and non-inland water bodies.

\subsection{Degree of urbanization}

Degree of urbanization at participant's residence municipality was determined by the degree of urbanization (DGUR) (European Comission, 2013) attributed to the geocoded residential address of each study participant. DGUR is a European dataset that classifies census communes into urbanization categories according to their population density and the total population of each commune and its surrounding areas. The three categories of DGUR (densely populated, intermediate area, and thinly populated area) were dichotomized with cut-off at "less than densely populated".

\subsection{Covariates}

We selected the following a priori covariates based on previous literature: gender, age, education completed, birth place, type of health insurance, marital status, and indicators of household (based on the occupation of the main person of each household) and neighborhood (the percentage of the population with education higher than secondary in the participant's census track) socioeconomic status (SES).

\subsection{Main analysis}

Logistic regression models were developed to estimate the associations between pairs of indicators of natural outdoor environments and health outcomes with adjustment for covariates and also between indicators of natural outdoor environments and physical activity. Negative binominal models were developed to estimate the association between indicators of natural outdoor environments and social support. For all these models, each of the natural outdoor environment indicators was included in separate models. For surrounding greenness, associations were expressed per interquartile range (IQR) increase in the exposure.

Interaction terms were included between indicators of natural outdoor environments and (i) degree of urbanization, (ii) gender, and (iii) household SES to investigate whether statistically significant effect modification emerged. Stratified analyses by degree of urbanization, gender, and SES were fitted to explore if the associations changed across the strata.

Problems in the geocoding process of residential addresses led to missing data in the natural outdoor environment and degree of urbanization variables ( $n=615,6.54 \%$ ). This especially affected the Aran region and other rural areas. As there was not enough information to impute these variables, observations with missing values were excluded from the analyses. To account for other missing covariates and health information for the rest of participants $(n=8793)$, we conducted multiple imputation (Supplementary materials - page 8).

\subsection{Sensitivity analyses}

\subsubsection{Buffer size for abstracting natural outdoor environment indicators}

To evaluate the robustness of our findings to our selection of $300 \mathrm{~m}$ buffer size, we characterized the indicators in buffers of $100 \mathrm{~m}, 500 \mathrm{~m}$, and $1 \mathrm{~km}$ and repeated the aforementioned main analyses.

\subsubsection{Visits to mental health specialists}

We derived visits to mental health specialists as visits to either psychologist or psychiatrist during the last year. To evaluate the robustness of our findings, we derived visits to psychologist and psychiatrist separately and repeated the aforementioned main analyses.

\subsubsection{Missing data in the natural outdoor environment and degree of urbanization}

We excluded participants with missing data in the natural outdoor environment and degree of urbanization from the analyses and then imputed the missing data for the rest of participants. To evaluate the robustness of our findings, we imputed all the missing data for all participants (including those with missing geocoded address) and repeated the aforementioned main analyses.

\section{Results}

\subsection{Study population}

Of 18,525 adults who were approached, 9408 (50.79\%) completed the survey, from whose 8793 (93.46\%) were able to be geocoded. The characteristics of study participants, prevalence of outcomes, and description of indicators of natural outdoor environment are presented in Table 1. There were no notable differences in the characteristics of the sample between observed and imputed values (Supplementary material - Table 1).

\subsection{Main analysis}

The indicators of access to green spaces and of surrounding greenness within $300 \mathrm{~m}$ were highly correlated (Table 2) and also the indicators of exposure to green spaces and degree of urbanization (Table 2).

The estimates of the associations between natural outdoor environments and health within $300 \mathrm{~m}$ are shown in Table 3. The estimates were consistently showing that higher green space exposure was associated with lower likelihoods of poor health, as odds ratios were below 1.00. However, only surrounding greenness was statistically significantly associated with lower likelihoods of poor health across all the health indicators (Table 3).

Residential proximity to blue spaces was not associated with lower likelihoods of poor health. Sensitivity analyses showed consistent results for different buffer sizes ( $100 \mathrm{~m}, 500 \mathrm{~m}$, and $1 \mathrm{~km}$ ) (Supplementary material - Table 2 ), for visits to psychologist and psychiatrist separately, and when analyzing the database with imputed natural outdoor environment and degree of urbanization (data not shown). Moreover, while exposure to green spaces was not associated with physical activity and social support, access to blue spaces was associated with more social support (Table 3). As neither physical activity or social support was associated with exposure to green spaces, and blue spaces were not with health indicators, we did not investigate further the hypothesized mediation effects of physical activity and social support. The analyses of the associations between self-perceived general health and green spaces, showed complete mediation by each of the mental health 
Table 1

Characteristics of the study participants included in the analysis.

\begin{tabular}{|c|c|c|}
\hline & $\mathrm{n}$ & Proportion/median ${ }^{\mathrm{a}}$ \\
\hline Gender & 8793 & \\
\hline Male & & 49.94 \\
\hline Female & & 50.06 \\
\hline Age & 8793 & $48.00(34.00,64.00)$ \\
\hline Education & 8788 & \\
\hline Primary or without studies & & 28.25 \\
\hline Secondary & & 54.19 \\
\hline University & & 17.56 \\
\hline Marital status & 8793 & \\
\hline Single & & 27.20 \\
\hline Married & & 58.58 \\
\hline Widower & & 8.83 \\
\hline Separated/divorced & & 5.39 \\
\hline Household socioeconomic status & 8463 & \\
\hline High & & 23.97 \\
\hline Intermediate & & 57.88 \\
\hline Low & & 18.15 \\
\hline Percentage of population with university studies & 8169 & $13.55(9.25,20.70)$ \\
\hline Type of health insurance & 8786 & \\
\hline Only national health service & & 75.47 \\
\hline Private or public and private & & 24.53 \\
\hline Birth place & 8751 & \\
\hline Spain and other developed countries & & 88.79 \\
\hline Countries under development & & 11.21 \\
\hline Less than good self-perceived general health & 8793 & \\
\hline No, so self-perceived healthy & & 75.99 \\
\hline Yes, so not self-perceived healthy & & 24.01 \\
\hline Perceived risk of poor mental health & 8478 & \\
\hline No & & 88.04 \\
\hline Yes & & 11.96 \\
\hline Perceived depression and/or anxiety & 8792 & \\
\hline No & & 79.60 \\
\hline Yes & & 20.40 \\
\hline Visits to mental health specialists & 8793 & \\
\hline No & & 93.90 \\
\hline Yes & & 6.10 \\
\hline Intake of tranquilizers or sedatives & 8793 & \\
\hline No & & 89.83 \\
\hline Yes & & 10.17 \\
\hline Intake of antidepressants & 8793 & \\
\hline No & & 91.49 \\
\hline Yes & & 8.51 \\
\hline Intake of sleeping medication & 8793 & \\
\hline No & & 89.91 \\
\hline Yes & & 10.09 \\
\hline Degree of urbanization & 8793 & \\
\hline Non-densely populated areas & & 50.96 \\
\hline Densely populated areas & & 49.04 \\
\hline Surrounding greenness within $300 \mathrm{~m}$ & 8793 & $0.16(0.13,0.21)$ \\
\hline Access to green spaces within $300 \mathrm{~m}$ & 8793 & \\
\hline None & & 39.75 \\
\hline Yes & & 60.25 \\
\hline Access to blue spaces within $300 \mathrm{~m}$ & 8793 & \\
\hline None & & 94.17 \\
\hline Yes & & 5.83 \\
\hline Social support & 5010 & $50.00(44.00,54.00)$ \\
\hline \multicolumn{3}{|l|}{ Achieving physical activity recommendations } \\
\hline None & 8793 & 76.56 \\
\hline Yes & & 23.44 \\
\hline
\end{tabular}

a Proportions are shown for all the variables with the exception of age, percentage of population with university studies and surrounding greenness at $300 \mathrm{~m}$ and social support where the median (1st, 3rd quartile) is reported.

indicators, i.e. in most of the cases the green space indicators no longer had added predictive value (Supplementary material - Table 3).

No consistent evidence was found for degree of urbanization as an effect modifier of the association between natural outdoor environments and health. None of the interaction terms between each of the natural outdoor environment indicators and degree of urbanization was statistically significant in the models (Table 3). However, the estimates of the non-densely populated areas showed slightly stronger beneficial associations with green spaces compared with the estimates
Table 2

Polychoric correlations between exposure variables.

\begin{tabular}{|c|c|c|}
\hline & $\begin{array}{l}\text { Surrounding greenness } \\
\text { within } 300 \mathrm{~m}\end{array}$ & $\begin{array}{l}\text { Degree of } \\
\text { urbanization }\end{array}$ \\
\hline Surrounding greenness within $300 \mathrm{~m}$ & - & $0.72(0.71,0.74)$ \\
\hline Access to green spaces within $300 \mathrm{~m}$ & $0.81(0.79,0.82)$ & $0.76(0.75,0.78)$ \\
\hline
\end{tabular}

of densely populated areas (Table 4). Similarly, only one interaction term for gender was statistically significant, and the associations for women were slightly stronger than those for men (Table 5). No evidence was found for SES as an effect modifier of the association between green spaces and health. The estimates of the models stratified by socioeconomic status did not show consistent differences between the health indicators (Supplementary material - Table 4).

\section{Discussion}

This study investigated the association between natural outdoor environments, separately for green and blue spaces, and health, including both general and mental health. We also evaluated the potential for modification of these associations by the degree of urbanization, gender, and SES and mediation of these associations by physical activity and social contacts. We found that higher residential surrounding greenness and living in vicinity of green spaces were associated with better health, both general and mental. We also observed some indications for slightly larger benefits of green exposure for women and those living in nondensely populated areas. However, the corresponding interaction terms were not statistically significant. No indications of varying benefits for household SES were found. The findings for living close to blue spaces were not conclusive. Moreover, no association was found between green space exposure and physical activity or social support.

Our findings are in line with those of previous studies, which showed similar beneficial associations between green spaces and selfperceived general health (Maas et al., 2006; De Vries et al., 2013, 2003; Maas et al., 2009; White et al., 2013b) and green spaces and mental health (De Vries et al., 2003, 2013; Maas et al., 2009; White et al., 2013a; Alcock et al., 2014; Beyer et al., 2014; Nutsford et al., 2013; Astell-Burt et al., 2014; White et al., 2013b). However, none of the previous studies investigated a wide range of mental health indicators (including medication), or the associations in a southern Europe population, very few evaluated different effect modifiers and mediators at the same time, and only one studied green and blue spaces simultaneously (White et al., 2013b).

We observed statistically significant associations between surrounding greenness and a wide range of health indicators, but not for access to green spaces. These findings might indicate towards the importance of small green spaces such as street trees, paths, greenways or gardens, which are captured by the surrounding greenness indicator, but not by the access to green space indicators (Mitchell et al., 2011). It could be that this type of greenness provides more effective opportunities for restoration/stress reduction (as micro-restorative settings) through for example visual access, than other types of green spaces. This would agree with previous research exposing the role of nearby natural outdoor environments (e.g. views of trees from a window or listening to birds) in restoration processes (De Vries et al., 2013; Kaplan, 2001). However, since our data do not provide any information on the use and specific characteristics of these green spaces, alternative explanations cannot be ruled out.

The available evidence on the impact of blue spaces on health is still scarce. Although a few studies have suggested that exposure to blue spaces could be associated with health (De Vries et al., 2003; Wheeler et al., 2012; White et al., 2013b), we did not find any consistent association. Only around $6 \%$ of our study participants lived within $300 \mathrm{~m}$ of a blue space which could have limited our statistical power for these analyses. 
Table 3

Adjusted ${ }^{\dagger}$ associations between natural outdoor environments within $300 \mathrm{~m}$ and health (general and mental) and mediators.

\begin{tabular}{|c|c|c|c|c|c|c|}
\hline & $\begin{array}{l}\text { Surrounding } \\
\text { greenness OR } \\
(95 \% \mathrm{CI})\end{array}$ & $\begin{array}{l}\text { p-Value of interaction } \\
\text { with urbanization }^{\mathrm{a}}\end{array}$ & $\begin{array}{l}\text { Access to green } \\
\text { spaces OR }{ }^{\S} \\
(95 \% \mathrm{CI})\end{array}$ & $\begin{array}{l}\text { p-Value of interaction } \\
\text { with urbanization }^{\text {b }}\end{array}$ & $\begin{array}{l}\text { Access to blue } \\
\text { spaces } \mathrm{OR}^{\S} \\
(95 \% \mathrm{CI})\end{array}$ & $\begin{array}{l}\text { p-Value of interaction } \\
\text { with urbanization }^{c}\end{array}$ \\
\hline \multicolumn{7}{|l|}{ Health indicators } \\
\hline $\begin{array}{l}\text { Less than good self-perceived general } \\
\text { health }\end{array}$ & $0.90(0.83,0.98)^{*}$ & 0.75 & $0.95(0.83,1.08)$ & 0.26 & $0.82(0.65,1.05)$ & 0.72 \\
\hline Perceived risk of poor mental health & $0.79(0.71,0.88)^{*}$ & 0.88 & $0.93(0.79,1.09)$ & 0.64 & $1.13(0.86,1.49)$ & 0.81 \\
\hline Perceived depression and/or anxiety & $0.81(0.75,0.88)^{*}$ & 0.26 & $0.86(0.76,0.98)^{*}$ & 0.59 & $1.13(0.90,1.41)$ & 0.81 \\
\hline Visits to mental health specialists & $0.80(0.69,0.92)^{*}$ & 0.73 & $0.79(0.63,0.98)^{*}$ & 0.51 & $1.30(0.92,1.84)$ & 0.76 \\
\hline Intake of tranquilizers or sedatives & $0.88(0.79,0.99)^{*}$ & 0.15 & $0.93(0.78,1.11)$ & 0.35 & $0.85(0.61,1.17)$ & 0.94 \\
\hline Intake of antidepressants & $0.80(0.71,0.91)^{*}$ & 0.23 & $0.87(0.72,1.05)$ & 0.17 & $0.84(0.59,1.19)$ & 0.83 \\
\hline Intake of sleeping medication & $0.89(0.79,0.99)^{*}$ & 0.71 & $1.03(0.86,1.24)$ & 0.69 & $0.95(0.69,1.31)$ & 0.27 \\
\hline \multicolumn{7}{|l|}{ Mediators } \\
\hline Social support & $0.98(0.93,1.04)$ & - & $1.04(0.96,1.13)$ & - & $1.22(1.06,1.41)^{*}$ & - \\
\hline Physical activity & $1.01(0.93,1.09)$ & - & $1.02(0.89,1.18)$ & - & $0.99(0.78,1.26)$ & - \\
\hline \multicolumn{7}{|c|}{$\dagger$ Models adjusted for gender, age, education, marital status, socioeconomic status, percentage of population with university studies, health insurance, origin, and degree of urbanization } \\
\hline \multicolumn{7}{|c|}{$\S$ Odds ratio (OR) reported for all the variables with the exception of social support, where incidence rate ratio is reported. } \\
\hline \multicolumn{7}{|c|}{ * p-value $<0.05$} \\
\hline \multicolumn{7}{|c|}{ a Multiplicative interaction p-value between surrounding greenness and degree of urbanization. } \\
\hline \multicolumn{7}{|c|}{ b Multiplicative interaction p-value between access to green spaces and degree of urbanization. } \\
\hline
\end{tabular}

When stratified by socioeconomic status all our estimates remained consistent with the main effects, which could provide more confidence that our findings were less likely to have been biased by residual SES confounding. However, a number of previous studies have reported modification of health benefits by SES with lower SES groups benefiting more (Maas et al., 2006; Mitchell and Popham, 2007; De Vries et al., 2003; Mitchell and Popham, 2008; Dadvand et al., 2014) but we did not see this. When stratified by gender and degree of urbanization, there was a tendency for slightly stronger associations between green spaces and health for women and those living in non-densely populated areas, but this was not statistical significant. The small differences we found by gender are consistent with previous findings that have suggested that women use green spaces more because they are more likely to take care of older people and children than men (Tamosiunas et al., 2014). However, some other studies have found that green spaces are more used and more beneficial for males (Richardson and Mitchell,

Table 4

Adjusted $^{\mathrm{a}}$ associations between natural outdoor environments within $300 \mathrm{~m}$ and health (general and mental) separately by urbanity context.

\begin{tabular}{|c|c|c|}
\hline Health indicators & $\begin{array}{l}\text { Surrounding } \\
\text { greenness } \\
\text { OR }(95 \% \mathrm{CI})\end{array}$ & $\begin{array}{l}\text { Access to green } \\
\text { spaces } \\
\text { OR }(95 \% \mathrm{CI})\end{array}$ \\
\hline \multicolumn{3}{|l|}{ Non-densely populated areas } \\
\hline $\begin{array}{l}\text { Less than good self-perceived } \\
\text { general health }\end{array}$ & $0.91(0.83,1.00)$ & $1.06(0.83,1.35)$ \\
\hline Perceived risk of poor mental health & $0.78(0.68,0.89)^{*}$ & $0.95(0.70,1.30)$ \\
\hline Perceived depression and/or anxiety & $0.79(0.71,0.87)^{*}$ & $0.80(0.63,1.01)$ \\
\hline Visits to mental health specialists & $0.79(0.66,0.94)^{*}$ & $0.68(0.46,1.00)^{*}$ \\
\hline Intake of tranquilizers or sedatives & $0.85(0.75,0.97)^{*}$ & $0.80(0.59,1.09)$ \\
\hline Intake of antidepressants & $0.77(0.66,0.89)^{*}$ & $0.69(0.50,0.96)^{*}$ \\
\hline Intake of sleeping medication & $0.88(0.77,1.01)$ & $0.95(0.68,1.33)$ \\
\hline \multicolumn{3}{|l|}{ Densely populated areas } \\
\hline $\begin{array}{l}\text { Less than good self-perceived } \\
\text { general health }\end{array}$ & $0.88(0.75,1.04)$ & $0.90(0.76,1.06)$ \\
\hline Perceived risk of poor mental health & $0.81(0.67,0.99)^{*}$ & $0.92(0.75,1.11)$ \\
\hline Perceived depression and/or anxiety & $0.88(0.75,1.03)$ & $0.90(0.77,1.06)$ \\
\hline Visits to mental health specialists & $0.83(0.65,1.07)$ & $0.84(0.65,1.09)$ \\
\hline Intake of tranquilizers or sedatives & $1.01(0.82,1.24)$ & $1.00(0.81,1.24)$ \\
\hline Intake of antidepressants & $0.91(0.73,1.13)$ & $0.96(0.77,1.21)$ \\
\hline Intake of sleeping medication & $0.93(0.75,1.15)$ & $1.07(0.86,1.34)$ \\
\hline
\end{tabular}

a Models adjusted for gender, age, education, marital status, socioeconomic status, percentage of population with university studies, health insurance and origin.

$*$ p-value $\leq 0.05$.
2010). The small differences we have found by degree of urbanization are consistent with previous findings (Mitchell and Popham, 2007; De Vries et al., 2003). In general, however, we believe that the consistency of our main estimates with the estimates in the stratified analyses shows the robustness of our main results.

We did not find any association of green spaces with physical activity and social support, questioning any possible mediation effect of these factors. Previous studies (De Vries et al., 2013; Maas et al., 2009; Sugiyama et al., 2008) reported a positive association between green spaces and social support which was not replicated by our study. Meanwhile, our observed lack of association for physical activity is in line with some previous studies (De Vries et al., 2013; Maas et al., 2008) but not with others (Sugiyama et al., 2008; Richardson et al., 2013). However, based on our results, we hypothesize that, instead of physical activity and social support, restoration and stress reduction could be alternative pathways that may underlie the associations between green spaces and health, as others have suggested (De Vries et al., 2013;

Table 5

Adjusted $^{\mathrm{a}}$ associations between natural outdoor environments within $300 \mathrm{~m}$ and health (general and mental) separately by gender.

\begin{tabular}{lll}
\hline Health indicators & $\begin{array}{l}\text { Surrounding } \\
\text { greenness } \\
\text { OR }(95 \% \mathrm{CI})\end{array}$ & $\begin{array}{l}\text { Access to green } \\
\text { spaces } \\
\text { OR }(95 \% \mathrm{CI})\end{array}$ \\
\hline $\begin{array}{ll}\text { Males } \\
\begin{array}{l}\text { Less than good self-perceived } \\
\text { general health }\end{array}\end{array}$ & $0.91(0.81,1.03)$ & $0.95(0.78,1.15)$ \\
Perceived risk of poor mental health & $0.82(0.70,0.98)^{*}$ & $0.98(0.76,1.26)$ \\
Perceived depression and/or anxiety & $0.82(0.71,0.93)^{*}$ & $0.96(0.77,1.18)$ \\
Visits to mental health specialists & $0.81(0.65,1.02)$ & $0.92(0.66,1.28)$ \\
Intake of tranquilizers or sedatives & $0.74(0.61,0.89)^{*}$ & $0.95(0.71,1.26)$ \\
Intake of antidepressants & $0.75(0.60,0.94)^{*}$ & $1.02(0.73,1.43)$ \\
Intake of sleeping medication & $0.83(0.69,1.00)^{*}$ & $1.13(0.83,1.53)$ \\
$\quad \begin{array}{l}\text { Females } \\
\text { Self-perceived general health }\end{array}$ & $0.89(0.80,0.99)^{*}$ & $0.95(0.79,1.14)$ \\
Perceived risk of poor mental health & $0.77(0.67,0.88)^{*}$ & $0.89(0.72,1.10)$ \\
Perceived depression and/or anxiety & $0.80(0.72,0.89)^{*}$ & $0.81(0.68,0.96)^{*}$ \\
Visits to mental health specialists & $0.79(0.65,0.95)^{*}$ & $0.70(0.52,0.93)^{*}$ \\
Intake of tranquilizers or sedatives & $0.96(0.85,1.10)$ & $0.92(0.73,1.15)$ \\
Intake of antidepressants & $0.82(0.71,0.95)^{*}$ & $0.80(0.64,1.01)$ \\
Intake of sleeping medication & $0.91(0.80,1.05)$ & $0.98(0.78,1.24)$ \\
\hline
\end{tabular}

a Models adjusted for age, education, marital status, socioeconomic status, percentage of population with university studies, health insurance, origin, and degree of urbanization. * p-value $\leq 0.05$. 
Sugiyama et al., 2008). The strong associations between mental health indicators and self-perceived general, showing complete mediation by mental health indicators in our studied models, are as expected and according to previous research (De Vries et al., 2013).

Our analyses were based on a large population-based sample residing in areas with different degrees of urbanity enabling this study to be one of the firsts to simultaneously evaluate the aforementioned associations, mediators, and effect modifiers in order to provide a mechanistic insight on the health benefits of natural outdoor environment separately for green and blue spaces. Moreover, other strengths of our study include: the use of standardized and validated questionnaires to obtain health indicators, the inclusion of various health indicators, and the use of objective and standardized measures of exposure to natural outdoor environments.

Our study, however, faces some limitations. Our study is not able to establish if the exposures preceded the outcomes because of its crosssectional design. We cannot completely rule out self-selection bias, although we have adjusted for its potential factors as much as possible. Our health indicators were based on self-reported questionnaires and the assessment of the outcomes was not confirmed by health professionals which could result in outcome misclassification. Our objective measures of exposure do not capture natural outdoor environment qualitative characteristics. For example, they do not include information on safety, esthetics, amenities, or maintenance, that others have found that affect people's use of green spaces (McCormack et al., 2010). Moreover, the use of NDVI images at a single point in time (2013) assumes that the spatial distribution of NDVI across our study region remains constant over the study period, as has been shown in the case of this region over seasons and years (Dadvand et al., 2012b). Also, we had limited power to test for interaction.

\section{Conclusions}

In conclusion, our study provides evidence that green spaces are associated with better self-perceived general and mental health across different degrees of urbanization, socioeconomic statuses, and genders, and that physical activity and social support were unlikely to be mediators as they did not show an association with green space indicators. Our observations for health benefits of blue spaces were not conclusive. Our findings for green spaces, together with evidence of previous studies, provide further indications for the importance of these spaces in improving our living environments and making them more salutogenic. More studies are needed to include a wider range of exposure to blue spaces, objective measurements of outcomes, considerations of the natural outdoor environments around work/study places, measures of exposure that include qualitative characteristics, and longitudinal data. Future research should further investigate all the possible mechanisms together underlying the association between natural outdoor environments and health, especially mental health.

\section{Contributorship}

MTM participated in the conception, design and planning of the study, performed literature revision, data analysis, interpretation of the results and manuscript writing. PD contributed in the conception, analysis and writing of the manuscript. MC contributed in the geocoding process, derived measures of natural outdoor environment exposure, degree of urbanization and household socioeconomic status, and contributed to manuscript writing. DM guided statistical analysis and contributed in manuscript writing. AM and AM supplied data, and advised on data analysis. XB advised on data analysis and contributed to manuscript writing. RG contributed in the conception of the study. MJN participated in the conception, design and planning of the study, supervised the data analysis, contributed in the interpretation of the results and in the revision of the manuscript. All authors saw and approved the final version of the manuscript.

\section{Funding}

This study has received funding from the European Community's Seventh Framework Programme (FP/2007-2013) under grant agreement no: 282996 (ENV.2011.1.2.3-2). Margarita Triguero-Mas is funded by a pre-doctoral grant from the Catalan Government (AGAUR FI-DGR2013). None of the funders had involvement in the design, analysis or interpretation of this study.

\section{Competing interests}

None.

\section{Appendix A. Supplementary data}

Supplementary data to this article can be found online at http://dx. doi.org/10.1016/j.envint.2015.01.012.

\section{References}

Adevi, A.A., Grahn, P., 2011. Attachment to certain natural environments: a basis for choice of recreational settings, activities and restoration from stress? Environ. Nat Resour. Res. 1, 36-52.

Alcañiz-Zanón, M., Mompart-Penina, A., Guillén-Estany, M., et al., 2014. Nuevo diseño de la Encuesta de Salud de Cataluña (2010-2014): un paso adelante en planificación y evaluación sanitaria. Gac. Sanit. 28, 338-340. http://dx.doi.org/10.1016/j.gaceta. 2013.12.004.

Alcock, I., White, M.P., Wheeler, B.W., et al., 2014. Longitudinal effects on mental health of moving to greener and less green urban areas. Environ. Sci. Technol. 48, 1247-1255. http://dx.doi.org/10.1021/es403688w.

Annerstedt, M., Östergren, P.-O., Björk, J., et al., 2012. Green qualities in the neighbourhood and mental health-results from a longitudinal cohort study in Southern Sweden. BMC Public Health 12, 337.

Astell-Burt, T., Mitchell, R., Hartig, T., 2014. The association between green space and mental health varies across the lifecourse. A longitudinal study. J. Epidemiol. Community Health 68, 578-583. http://dx.doi.org/10.1136/jech-2013-203767.

Balseviciene, B., Sinkariova, L., Grazuleviciene, R., et al., 2014. Impact of residential greenness on preschool children's emotional and behavioral problems. Int. J. Environ. Res. Public Health 11, 6757-6770. http://dx.doi.org/10.3390/ijerph110706757.

Beyer, K., Kaltenbach, A., Szabo, A., et al., 2014. Exposure to neighborhood green space and mental health: evidence from the survey of the health of Wisconsin. Int. J. Environ. Res. Public Health 11, 3453-3472. http://dx.doi.org/10.3390/ijerph110303453.

Broadhead, W.E., Gehlbach, S., de Gruy, F.V., et al., 1988. The Duke-UNC Functional Social Support Questionnaire. Med. Care 26.

Chang, C.-Y., Chen, P.-K., 2005. Human response to window views and indoor plants in the workplace. HortSci. 40, 1354-1359.

Dadvand, P., de Nazelle, A., Triguero-Mas, M., et al., 2012a. Surrounding greenness and exposure to air pollution during pregnancy: an analysis of personal monitoring data. Environ. Health Perspect. 120, 1286-1290. http://dx.doi.org/10.1289/ehp.1104609.

Dadvand, P., Sunyer, J., Basagaña, X., et al., 2012b. Surrounding greenness and pregnancy outcomes in four Spanish birth cohorts. Environ. Health Perspect. 120, 1481-1487. http://dx.doi.org/10.1289/ehp.1205244.

Dadvand, P., Wright, J., Martinez, D., et al., 2014. Inequality, green spaces, and pregnant women: roles of ethnicity and individual and neighbourhood socioeconomic status. Environ. Int. 71, 101-108. http://dx.doi.org/10.1016/j.envint.2014.06.010.

De Vries, S., Verheij, R.A., Groenewegen, P.P., et al., 2003. Natural environments - healthy environments? An exploratory analysis of the relationship between greenspace and health. Environ. Plan. A 35, 1717-1731. http://dx.doi.org/10.1068/a35111.

De Vries, S., van Dillen, S.M.E., Groenewegen, P.P., et al., 2013. Streetscape greenery and health: stress, social cohesion and physical activity as mediators. Soc. Sci. Med. 94 26-33. http://dx.doi.org/10.1016/j.socscimed.2013.06.030.

Donovan, G.H., Michael, Y.L., Butry, D.T., et al., 2011. Urban trees and the risk of poor birth outcomes. Health Place 17, 390-393. http://dx.doi.org/10.1016/j.healthplace.2010.11. 004.

European Comission, 2013. Eurostat. Degree of Urbanisation (DGUR). http://ec.europa.eu/ eurostat/ramon/miscellaneous/index.cfm?TargetUrl=DSP_DEGURBA (accessed 23 Jan 2013).

European Commission, 2001. Towards a local sustainability profile. European Common Indicators. Methodology Sheets.

Generalitat de Catalunya, 2014. Idescat. Institut d'Estadística de Catalunya (http://www idescat.cat/(accessed 3 Sep 2014)).

Goldberg, D., Williams, P., 1991. A User's Guide to the General Health Questionnaire NFER-Nelson, Windsor, UK

Grahn, P., Stigsdotter, U.A., 2003. Landscape planning and stress. Urban For. Urban Green 2, 1-18.

Hartig, T., Mitchell, R., de Vries, S., et al., 2014. Nature and health. Annu. Rev. Public Health 35, 207-228. http://dx.doi.org/10.1146/annurev-publhealth-032013-182443.

Heartbeat Wales, 1989. Welsh Heart Health Survey 1985: Protocol and Questionnaire. Health Promotion Authority for Wales, Wales. 
Kaplan, R., 2001. The nature of the view from home psychological benefits. Environ. Behav. 33, 507-542.

Maas, J., Verheij, R., Groenewegen, P., et al., 2006. Green space, urbanity, and health: how strong is the relation? J. Epidemiol. Community Health 60, 587-592.

Maas, J., Verheij, R.A., Spreeuwenberg, P., et al., 2008. Physical activity as a possible mechanism behind the relationship between green space and health: a multilevel analysis. BMC Public Health 8, 206. http://dx.doi.org/10.1186/1471-2458-8-206.

Maas, J., van Dillen, S.M.E., Verheij, R.A., et al., 2009. Social contacts as a possible mechanism behind the relation between green space and health. Health Place 15 586-595. http://dx.doi.org/10.1016/j.healthplace.2008.09.006.

McCormack, G.R., Rock, M., Toohey, A.M., et al., 2010. Characteristics of urban parks associated with park use and physical activity: a review of qualitative research. Health Place 16, 712-726. http://dx.doi.org/10.1016/j.healthplace.2010.03.003.

Mitchell, R., Popham, F., 2007. Greenspace, urbanity and health: relationships in England. J. Epidemiol. Community Health 61, 681-683. http://dx.doi.org/10.1136/jech.2006. 053553.

Mitchell, R., Popham, F., 2008. Effect of exposure to natural environment on health inequalities: an observational population study. Lancet 372, 1655-1660.

Mitchell, R., Astell-Burt, T., Richardson, E., 2011. A comparison of green space indicators for epidemiological research. J. Epidemiol. Community Health 65, 853-858. http:// dx.doi.org/10.1136/jech.2010.119172.

Nieuwenhuijsen, M.J., Kruize, H., Gidlow, C., et al., 2014. Positive health effects of the natural outdoor environment in typical populations in different regions in Europe (PHENOTYPE): a study programme protocol. BMJ Open 4, e004951.

Nutsford, D., Pearson, A.L., Kingham, S., 2013. An ecological study investigating the association between access to urban green space and mental health. Public Health 127, 1005-1011. http://dx.doi.org/10.1016/j.puhe.2013.08.016.

Pereira, G., Christian, H., Foster, S., et al., 2013. The association between neighborhood greenness and weight status: an observational study in Perth Western Australia. Environ. Health 12,49

Pino, L., González-Vélez, A.E., Prieto-Flores, M.-E., et al., 2014. Self-perceived health and quality of life by activity status in community-dwelling older adults: activity status in older adults. Geriatr. Gerontol. Int. 14, 464-473. http://dx.doi.org/10.1111/ggi. 12119.

Reklaitiene, R., Grazuleviciene, R., Dedele, A., et al., 2014. The relationship of green space, depressive symptoms and perceived general health in urban population. Scand J. Public Health http://dx.doi.org/10.1177/1403494814544494 (Published Online First: 12 August).

Richardson, E.A., Mitchell, R., 2010. Gender differences in relationships between urban green space and health in the United Kingdom. Soc. Sci. Med. 71, 568-575. http:// dx.doi.org/10.1016/j.socscimed.2010.04.015.
Richardson, E.A., Pearce, J., Mitchell, R., et al., 2013. Role of physical activity in the relationship between urban green space and health. Public Health 127, 318-324. http://dx. doi.org/10.1016/j.puhe.2013.01.004.

Rocha, K.B., Rodríguez-Sanz, M., Pérez, K., et al., 2013. Inequalities in the utilization of psychiatric and psychological services in Catalonia: a multilevel approach. Adm. Policy Ment. Health Ment. Health Serv. Res. 40, 355-363. http://dx.doi.org/10.1007/ s10488-012-0426-8.

Roe J., Thompson, C. Aspinall, P. et al, 2013. Green space and stress: evidence from cortisol measures in deprived urban communities. Int. J. Environ. Res. Public Health 10, 4086-4103. http://dx.doi.org/10.3390/ijerph10094086.

Strum, R., Cohen, D., 2014. Proximity to urban parks and mental health. J. Ment. Health Policy Econ. 17, 19-24.

Sugiyama, T., Leslie, E., Giles-Corti, B., et al., 2008. Associations of neighbourhood greenness with physical and mental health: do walking, social coherence and local social interaction explain the relationships? J. Epidemiol. Community Health 62, e9. http://dx.doi.org/10.1136/jech.2007.064287.

Tamosiunas, A., Grazuleviciene, R., Luksiene, D., et al., 2014. Accessibility and use of urban green spaces, and cardiovascular health: findings from a Kaunas cohort study. Environ. Health 13, 20. http://dx.doi.org/10.1186/1476-069X-13-20.

Ulrich, R., 1984. View through a window may influence recovery. Science 224, 224-225.

Van den Berg, A.E., Maas, J., Verheij, R.A., et al., 2010. Green space as a buffer between stressful life events and health. Soc. Sci. Med. 70, 1203-1210. http://dx.doi.org/10. 1016/j.socscimed.2010.01.002.

Ware, J.E., Donald Sherbourne, C., 1992. The MOS 36-Item Short-Form Health Survey (SF36). Med. Care 30.

Weier, J., Herring, D., 2014. Measuring Vegetation (NDVI \& EVI). http://earthobservatory. nasa.gov/Features/MeasuringVegetation (accessed 29 Aug2014).

Wheeler, B.W., White, M., Stahl-Timmins, W., et al., 2012. Does living by the coast improve health and wellbeing? Health Place 18, 1198-1201. http://dx.doi.org/10. 1016/j.healthplace.2012.06.015.

White, M.P., Alcock, I., Wheeler, B.W., et al., 2013a. Would you be happier living in a greener urban area? A fixed-effects analysis of panel data. Psychol. Sci. 24, 920-928.

White, M.P., Alcock, I., Wheeler, B.W., et al., 2013b. Coastal proximity, health and wellbeing: results from a longitudinal panel survey. Health Place 23, 97-103. http://dx. doi.org/10.1016/j.healthplace.2013.05.006.

World Health Organization, 2010. Global Recommendations on Physical Activity for Health. World Health Organization, Geneva, Switzerland. 